\title{
Comparative study of growth and yield of edible mushrooms, Schizophyllum commune Fr., Auricularia polytricha (Mont.) Sacc. and Lentinus squarrosulus Mont. on lignocellulosic substrates
}

\section{Ediriweera SS ${ }^{1}$, Wijesundera RLC $^{1}$, Nanayakkara $\mathbf{C M}^{\mathbf{1}}$ and Weerasena OVDSJ $^{2}$}

${ }^{1}$ Department of Plant Sciences, University of Colombo, Colombo 03, Sri Lanka.
${ }^{2}$ Institute of Biochemistry, Molecular Biology and Biotechnology, University of Colombo, Colombo 03, Sri Lanka.

Ediriweera SS, Wijesundera RLC, Nanayakkara CM, Weerasena OVDSJ 2015 - Comparative study of growth and yield of edible mushrooms, Schizophyllum commune Fr., Auricularia polytricha (Mont.) Sacc. and Lentinus squarrosulus Mont. on lignocellulosic substrates. Mycosphere 6(6), 760-765, Doi 10.5943/mycosphere/6/6/10

\begin{abstract}
Schizophyllum commune Fr., Auricularia polytricha (Mont.) Sacc. and Lentinus squarrosulus Mont. are edible mushrooms which are also proven to be medicinally important. This study was carried out to investigate the potential of locally available substrates to grow these mushrooms. Alternative substrates including dried banana leaves, coconut leaves, paddy straw and coir dust were compared with sawdust (rubber) which is the commonly used substrate for commercial production of mushrooms. Banana leaves, coconut leaves and paddy straw were cut into $1 \mathrm{~cm} \times 0.2 \mathrm{~cm}$ pieces. To each substrate, $10 \%(\mathrm{w} / \mathrm{w})$ rice bran, $2 \%(\mathrm{w} / \mathrm{w}) \mathrm{CaCO}_{3}$ and $0.2 \%$ (w/w) $\mathrm{MgSO}_{4}$ were added. The mixture was filled into 200 gauged polypropylene bags $(22 \mathrm{~cm} \times$ $12.5 \mathrm{~cm}$ ) and autoclaved. Each Bag was inoculated with a $1 \mathrm{~cm}^{2}$ block from the actively growing region of the mushroom culture maintained on PDA. After incubating under dark conditions at room temperature $\left(28 \pm 2{ }^{\circ} \mathrm{C}\right)$ and $78-80 \%$ relative humidity, mycelial growth rate and once fructification commenced, yield was determined. Highest rate for mycelial growth was observed in mixtures containing banana leaves for all three mushrooms. It was $10.345 \pm 0.02 \mathrm{~cm} /$ week for $S$. commune, $7.818 \pm 0.31 \mathrm{~cm} /$ week for A. polytricha and $10.895 \pm 0.30 \mathrm{~cm} /$ week for L. squarrosulus. Highest mushroom yield for $S$. commune was obtained in coconut leaf $(9.589 \pm 0.66 \mathrm{~g})$ and coir dust $(9.182 \pm 0.17 \mathrm{~g})$ containing mixtures. A yield of $25.054 \pm 5.18 \mathrm{~g}$ was recorded for $A$. polytricha in the medium prepared from banana leaves and sawdust (rubber) substrate was preferred by L. squarrosulus with a significantly higher yield of $54.079 \pm 3.61 \mathrm{~g}$.
\end{abstract}

Key words - alternative substrates - banana leaves - coconut leaves - mushroom yield - mycelial growth

\section{Introduction}

Edible mushrooms are the earliest form of microbial food known to mankind. They have gained wide popularity during recent times as "functional food" to complement and supplement a healthy diet as well as for their significant role in human disease control (Chang 1999, Khan et al. 2009). 
Schizophyllum commune Fr. is one of the commonly found fungi and has been isolated from all continents except Antarctica. The fungus usually grows abundantly during the rainy season and frequently appears on dead wood. It is an edible mushroom which belongs to the family Schizophyllaceae. S. commune is known to be a very good source of proteins, vitamins, lipids and mineral elements (Adejoye et al. 2007). The medicinal value of $S$. commune is also under investigation. A beta-glucan extracted from $S$. commune demonstrated potential anti-cancer effects when used in combination with other chemotherapeutic agents (Galena \& Vaghefi 2008). Auricularia polytricha (Mont.) Sacc. is also known to be a famous medicine in China which is ideal for dietetic prevention of hyperlipldaemia (Yang et al. 2002, Xu \& Yun 2003). It is rich in P, Mg, K and Se and with high dietary fiber content more than 50\% of the net weight (Ghorai et al. 2009). Research on Lentinus squarrosulus Mont. has shown that it is also medicinally important due to its excellent antimicrobial activity (Giri et al. 2012). According to Jonathan et al. (2011), the fresh fruiting body of L. squarrosulus consists of $16.87 \%$ crude protein, $22 \%$ crude fat, $6.73 \%$ crude fiber and $6.88 \%$ sugars and Potassium which is the most abundant mineral element. The protein content of L. squarrosulus is reported to be six times that of oranges (Adesina et al. 2011).

Commercial production of fresh edible mushrooms is a rapidly growing industrial activity that can be carried out in a large or small scale. It is an efficient and relatively short biological process of food protein recovery from negative value lignocellulosic materials, utilizing the degrading capabilities of mushrooms (Martínez-Carrera et al. 2000).

This study investigated the potential use of locally available substrates to grow S. commune, A. polytricha and L. squarrosulus especially sawdust, a frequently used substrate for growth of edible mushrooms in Sri Lanka. These species are not commercially grown in Sri Lanka currently and has a potential to be a viable industry with the development of value added products.

\section{Materials and methods}

\section{Mushroom strains}

Fruiting bodies of $S$. commune and A. polytricha were collected from IFS Sam Popham Arboretum Dambulla, Sri Lanka and L. squarrosulus from Matara, Sri Lanka. Specimens were initially identified by comparing morphological characters with published keys and guides (Coomaraswamy 1979, Coomaraswamy \& Kumarasingham 1988, Keizer 1998, Jordan 2004, Young 2005). Identity was confirmed by DNA extraction and sequencing (Ediriweera et al. 2014). The resultant sequences were analyzed and submitted to GenBank database (GenBank Accession Nos.: S. commune - KR706163, A. polytricha - KP943500 and L. squarrosulus - KP982902).

Tissue culturing was carried out in the laboratory where the stipe is surface sterilized and inner tissues $(3 \mathrm{~mm} \times 3 \mathrm{~mm})$ were cut and placed on the Potato Dextrose Agar (PDA) containing petriplates. Cultures were incubated at room temperature and subsequently pure cultures were prepared by sub culturing into new PDA plates (Leon et al. 2009).

\section{Effect of alternative substrates for mushroom production}

Several alternative substrates such as dried banana leaves (BL), coconut leaves (CL), paddy straw (PS) and coir dust (CD) were compared with Rubber sawdust (SD/control). One kilogram of above substrates was used separately. Banana leaves, coconut leaves and paddy straw were cut into $1 \mathrm{~cm} \times 0.2 \mathrm{~cm}$ pieces. To each substrate, $10 \%(\mathrm{w} / \mathrm{w})$ rice bran, $2 \%(\mathrm{w} / \mathrm{w}) \mathrm{CaCO}_{3}$ and $0.2 \%(\mathrm{w} / \mathrm{w})$ $\mathrm{MgSO}_{4}$ were added. The mixture was filled into 200 gauged polypropylene bags with dimensions of $22 \mathrm{~cm} \times 12.5 \mathrm{~cm}$. The bags were autoclaved for 15 minutes at $121{ }^{0} \mathrm{C} / 15 \mathrm{psi}$ and were left to cool overnight. Thereafter each bag was inoculated with a $1 \mathrm{~cm}^{2}$ block from the actively growing region of the mushroom culture maintained on PDA. Three replicates were maintained for each treatment.

The inoculated bags were incubated under dark conditions at room temperature $\left(28 \pm 2{ }^{0} \mathrm{C}\right)$ and weekly mycelial growth was measured to determine the mycelial growth rate. 


\section{Yeild data}

Growth rates were determined by measuring the mycelia growth front distal from the inoculum and by averaging the growth measurements at five equi-distant points around the circumference of each bag (Rajapakse et al. 2007). Subsequently the bags were cut opened and placed on a rack in a cool shed in which the humidity was well maintained $(80-82 \%)$ at room temperature $\left(28 \pm 2{ }^{0} \mathrm{C}\right)$. Water was sprayed on the cut opened surfaces of the bag to induce fructification. Once the fructification commenced, fully grown fruiting bodies (four days after primordial emergence) were harvested. Fresh weight of each harvest/flush was recorded (Oghenekara et al. 2009). The weekly mushroom yield was calculated accordingly.

\section{Statistical analysis}

The experiment was laid on a completely randomized design. The data was analyzed using MINITAB 14 statistical package.

\section{Results and Discussion}

Highest rate for mycelia growth for $S$. commune $(10.345 \pm 0.02 \mathrm{~cm} /$ week $)$, A. polytricha $(7.818 \pm 0.31 \mathrm{~cm} /$ week) and L. squarrosulus $(10.895 \pm 0.30 \mathrm{~cm} /$ week $)$ was observed in mixtures containing banana leaves (Figure 1). Even though $L$. squarrosulus grow in all the used substrates $S$. commune showed no signs of mycelial growth in the medium containing paddy straws and $A$. polytricha did not grow in the substrate prepared by sawdust (Fig. 1).

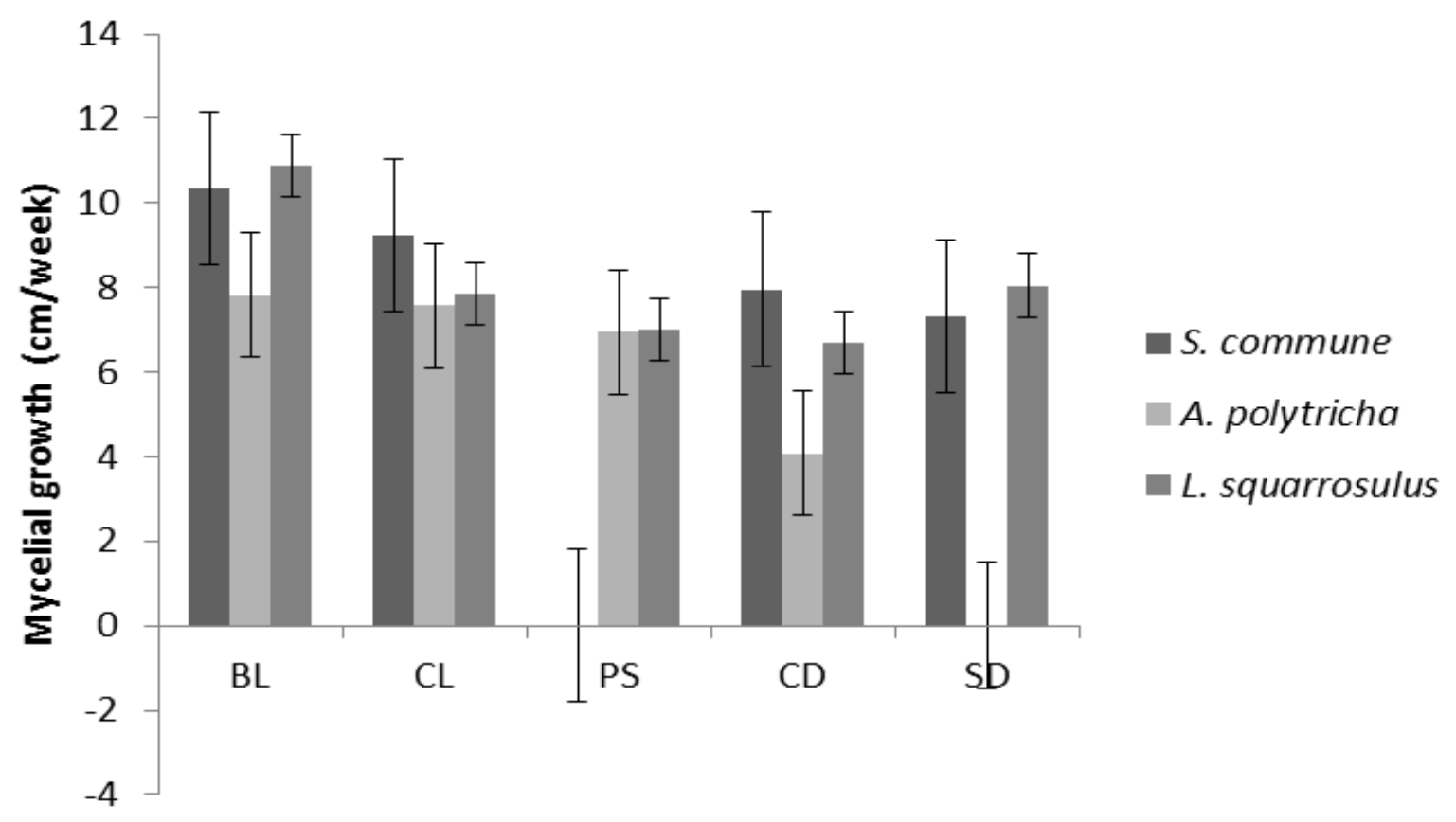

Fig. 1 - Mean mushroom mycelia growth in different mediums. BL - Banana leaves, CL - Coconut leaves, PS - Paddy straw, CD - Coir dust, SD - Sawdust (control)

Fruiting bodies of $S$. commune occurred after $20-25$ days of inoculation and it took $8-15$ days for one cycle production. Highest mushroom yield for $S$. commune was obtained for coconut leaves $(9.589 \pm 0.66 \mathrm{~g})$ and coir dust $(9.182 \pm 0.17 \mathrm{~g})$ containing mixtures which are significantly different from other used substrates $(\mathrm{P}=0.05)$. Banana leaves containing substrate gave the highest yield for $A$. polytricha $(25.054 \pm 5.18 \mathrm{~g})$ while paddy straw and coir dust containing media gave intermediate yields (Table 1, Figure 2). Fruiting bodies of A. polytricha occurred within $40-45$ days of inoculation while one cycle of production is $20-25$ days. 

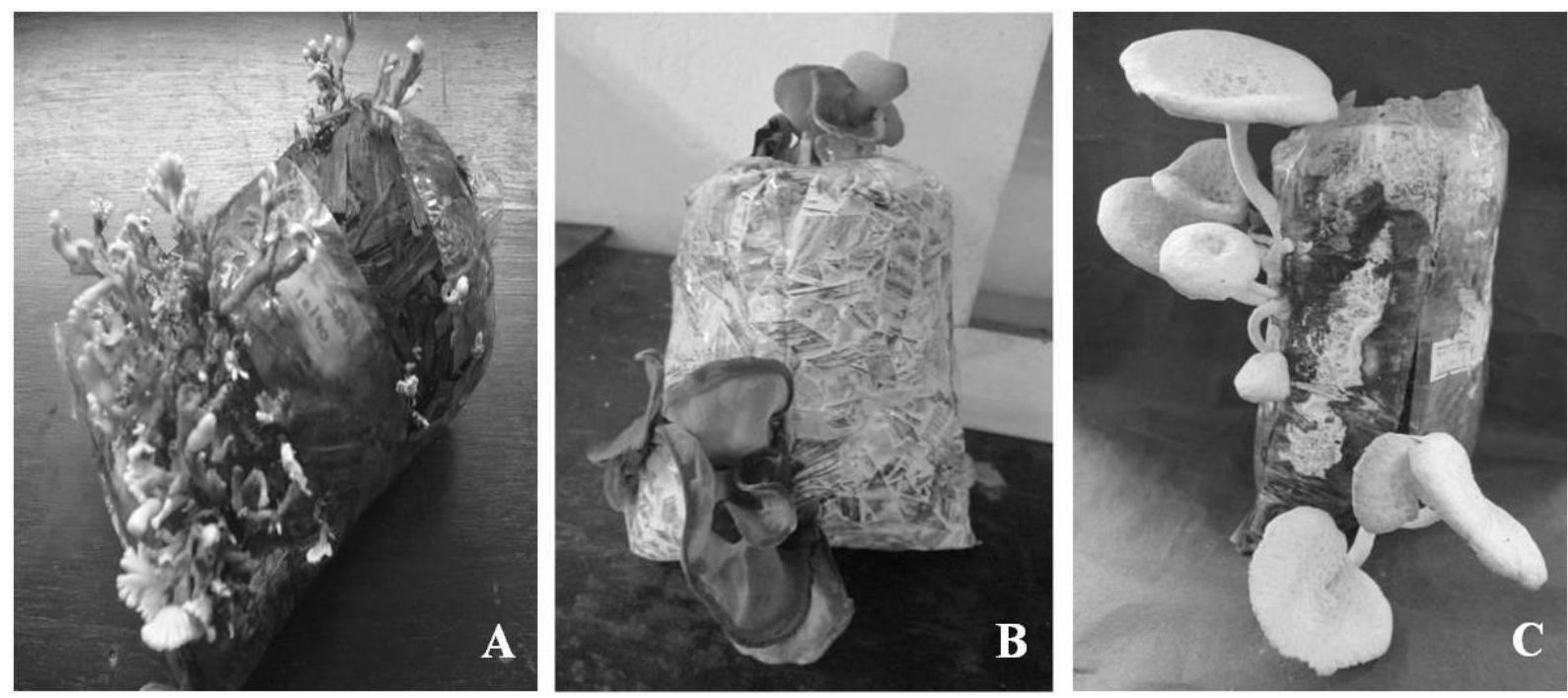

Fig. 2 - A. S. commune growing on the substrate prepared by coconut leaves, B. A. polytricha growing on the substrate prepared by banana leaves, C. L. squarrosulus growing on the substrate prepared by rubber sawdust.

When considering L. squarrosulus, most successful substrate was rubber sawdust containing medium with a significantly higher yield of $54.079 \pm 3.61 \mathrm{~g}$ (Table 1, Figure 2). In $L$. squarrosulus 50 - 60 days were taken for initiation of fruiting after inoculation while one cycle of production is $15-20$ days.

Table 1 Mean mushroom yield in different mediums

\begin{tabular}{llll}
\hline Main Ingredient in the & \multicolumn{2}{c}{ Mean Yeild (g) } \\
\cline { 2 - 4 } medium & S. commune & A. polytricha & L. squarrosulus \\
\hline Banana leaves (BL) & $3.294^{\mathrm{a}} \pm 0.03$ & $25.054^{\mathrm{a}} \pm 5.18$ & $9.800^{\mathrm{a}} \pm 2.55$ \\
Coconut leaves (CL) & $9.589^{\mathrm{b}} \pm 0.66$ & $0.000^{\mathrm{b}} \pm 0.00$ & $0.000^{\mathrm{a}} \pm 0.00$ \\
Paddy Straw (PS) & $0.000^{\mathrm{c}} \pm 0.00$ & $9.946^{\mathrm{b}} \pm 4.89$ & $27.351^{\mathrm{b}} \pm 5.17$ \\
Coir dust (CD) & $9.182^{\mathrm{b}} \pm 0.17$ & $11.097^{\mathrm{ab}} \pm 1.15$ & $5.525^{\mathrm{a}} \pm 1.28$ \\
Saw dust (SD) & $3.726^{\mathrm{a}} \pm 0.63$ & $0.000^{\mathrm{b}} \pm 0.00$ & $54.079^{\mathrm{c}} \pm 3.61$ \\
\hline
\end{tabular}

Each data point represents the mean of 3 replicates \pm standard error. Mean values denoted by the same letters along a column are not significantly different at 0.05 alpha levels.

In $A$. polytricha even though coconut leaves containing media exhibited highest mycelial growth rate, no fructification occurred in that medium. Similarly in a study carried out in Ghana for Pleurotus ostreatus, rice straw medium showed the highest yield while rice husk containing medium gave the fastest mycelia growth rate (Obodai et al. 2003). This indicates that mycelial growth and yield do not relate to each other since they have different requirements.

Same kind of study in Nigeria showed that L. squarrosulus can be cultivated in the laboratory on fruit tree waste especially the leaves of Spondias mombin and Citrus sinensis (Adesina et al. 2011). It was also successfully cultivated on cassava peels and Andropogon straw (Adesina et al. 2011).

To obtain a higher yield, the size of the bag could be increased, such as polypropylene bags with the dimensions $32.5 \mathrm{~cm} \times 17.5 \mathrm{~cm}$ which is the recommended size for the commercial production of oyster mushrooms by the Department of Agriculture, Sri Lanka. In addition for $S$. commune bags with a smaller diameter can also be tested since the fruit body is relatively small. Furthermore substrate can be placed on shallow trays and the yield can be compared as it increases the surface area for fructification. 
Substrate preparation is known as the "heart of process" thus a substrate that can provide adequate nutrients for mycelia growth and fructification plays a key role in determining the success of the cultivation (Rajapakse et al. 2007). Adding nutritional supplements can also induce a better yield. According to Oghenekaro et al. 2009 when L. squarrosulus was cultivated on the sawdust of five economic tropical tree species Brachystegia nigerica sawdust supplemented with $1 \% \mathrm{CaCO}_{3}$, $1 \%$ sugar and $20 \%$ wheat bran gave the highest yield. Some of the additives which were proven to be inducing fruiting are rice bran, cassava peels, carbohydrates such as glycogen, natural extracts like yeast and malt extract, ground pigeon pea, soybean, wheat, rye, millet, refined and crude vegetable oils and fish oil (Nawanze et al. 2005).

More experiments should be carried out based on these results for the production of reliable spawns so that this product can be commercialized. With the availability of a large amount of agricultural and forest waste as well as conducive climatic conditions this can be improved as a profitable industry in a country like Sri Lanka. It plays an important and a silent role as an environmental protection strategy. Most of the agricultural waste are either left in the field to rot or burned. By cultivating mushrooms on them those inedible wastes are transformed into edible biomass of high market value (Obodai et al. 2003). Furthermore the spent substrate from mushroom cultivation can be used as an animal feed (Obodai et al. 2003).

Based on mycelia growth rate and fruiting body yield obtained in this investigation, coconut leaves and coir dust based media can be recommended for the cultivation of $S$. commune, substrate made out of banana leaves for A. polytricha and rubber sawdust medium for L. squarrosulus.

\section{Acknowledgement}

Authors wish to acknowledge Mr. N.W. Gunasekara and Ms. M.D.M. Fernando for the support given to collect fungal samples. This research was funded by National Research Council of Sri Lanka (Research Grant: 11-040).

\section{References}

Adejoye OD, Adebayo-Tayo BC, Ogunjobi AA, Afolabi OO. 2007 - Physicochemical studies on Schizophyllum commune (Fries) a Nigerian fungus. World Appl Sci J. 2(1), 73-76.

Adesina FC, Fasidi IO, Adenipekun OC. 2011 - Cultivation and fruit body production of Lentinus squarrosulus Mont. (Singer) on bark and leaves of fruit trees supplemented with agricultural waste. Afr J Biotechnol. 10(22), 4608-4611.

Chang S. 1999 - World production of cultivated edible and medicinal mushrooms in 1997 with emphasis on Lentinus edodes (Berk.)Singer. In China. Int J Med Mushrooms 1, 291-300.

Coomaraswarmy U. 1979 - A handbook to the Agarics of Sri Lanka.Natural Resources, Energy and Science, Sri Lanka.

Coomaraswarmy U, Kumarasingham S. 1988 - A handbook to the macrofungi of Sri Lanka. Natural Resources, Energy and Science Authority, Sri Lanka.

Galena AE, Vaghefi SB. 2008 - Mushrooms and Prevention and Treatment of Cancer: InBotanical Medicine in Clinical Practice (ed. Watson RR and Preedy VR.), pp. 293-300. CABI, United Kingdom.

Ghorai S, Banik SP, Verma D, Chowdhury S, Mukherjee S, Khowala S. 2009 - Fungal biotechnology in food and feed processing. Food Res Int. 42, 577-587.

Giri S, Biswas G, Pradhan P, Mandal SC, Acharya K. 2012 - Antimicrobial activities of basidiocarps of wild edible mushrooms of West Bengal, India. Int J PharmTech Res. 4(4), $1555-1560$.

Jonathan SG, Amos-Tantua BMW, Olawuyi OJ. 2011 - Food values, heavy metal accumulation, aflatoxin contamination and detection of exo-polysaccharides in Lentinus squarrosulus Berk, a Nigerian mushroom. Afr J Agric Res. 6(13), 3007-3012.

Jordan M. 2004 - The encyclopedia of fungi of Britain and Europe. Frances Lincoln Ltd., London.

Keizer GJ.1998 - The complete encyclopedia of mushrooms. Rebo International, Netherlands. 
Khan MA, Khan LA, Hossain MS, Tania M, Uddin MN. 2009 - Investigation on nutritional composition of common edible and medicinal mushrooms cultivated in Bangladesh. Bangladesh J. Mushroom 3(1), 21-28.

Martínez-Carrera D, Aguilar A, Martínez W, Bonilla M, Morales P, Sobal M. 2000 - Commercial production and marketing of edible mushrooms cultivated on coffee pulp in Mexico. In Coffee Biotechnology and Quality (ed. T Sera, C Soccol, APandey,S Roussos), pp. 471488. Kluwer Academic Publishers,Dordrecht, Neterhlands.

Nawanze PI, Khan AU, Ameh JB, Umoh VJ. 2005 - The effect of the interaction of various spawn grains with different culture medium on carophore dry weights and stipe and pileus diameters of Lentinus squarrosulus (Mont.) Singer. Afr J Biotechnol. 4(7), 615-619.

Obodai M, Cleland-Okine J, Vowotor KA. 2003 - Comparative study on the growth and yield of Pleurotus ostreatus mushroom on different lignocellulosic by-products. J Ind Microbiol Biotechnol. 30, 146-149.

Oghenekaro AO, Okhuoya JA, Akpaja EO. 2009 - Growth of Lentinus squarrosulus (M.) Singer on sawdust of different tropical tree species. Afr J Food Sci. 3(1), 7-10.

Rajapakse JC, Rubasingha P, Dissanayake NN. 2007 - The potential of using cost-effective compost mixtures for Oyster mushroom (Pleurotus spp) cultivation in Sri Lanka. Tropical Agricultural Research \& Extension. 10, 29-32.

Xu C, Yun J. 2003 - Optimization of submerged-culture conditions for mycelia growth and exobiopolymer production by Auricularia polytricha (wood ear fungus) using the method of uniform design and regression analysis. Biotecnol Appl Biochem. 38, 193-199.

Yang B, Ha J, Jeong S, Jeon Y, Ra K, Das S, Yun J, Song C. 2002 - Hypolipidemic effect of an exo-biopolymer produced from submerged mycelia culture of Auricularia polytricha in rats. Biotecnol Lett. 24, 1319-1325.

Young AM. 2005 - A field guide to the fungi of Australia. University of New South Wales, Sydney, Australia. 